\title{
Generic and therapeutic substitution: a response to our critic
}

\author{
Mubarak Nasser Al Ameri • Miran Epstein • \\ Atholl Johnston
}

Received: 5 August 2011/Accepted: 5 September 2011/Published online: 17 September 2011

(C) Springer Science+Business Media B.V. 2011

\section{To the Editor}

In his response to our paper [1], Simoens complains that we "focus on the individual patient's perspective to the detriment of the societal perspective". He goes further to explicate what health economics, his field, perceives to be the 'societal perspective'. Resting on the premise of limited resources, it advocates ranking health technologies according to their cost-effectiveness. This entails that, in principle, substitution could maximise health outcomes in a given budget, even if the generic medicine were less effective than the reference medicine. Conversely, prescribing the more expensive reference medicine, which may perhaps improve the outcomes in the individual case, could result in overall decrease in population health [2].

We fully understand the rationale of health economics. However, we reject the conception of 'societal perspective' it implies. We are convinced that working in the assumption of limited resources/in an affluent society that has enough wealth to provide the best medical care for all/has nothing to do with good medicine or with any genuine 'societal perspective'.

It seems to us that the social role of health economics is to ensure that the distribution and redistribution of resources in our society will benefit the few at the expense of the many. We respect the determination of the minority to take good care of its interests. But we have other values.

We believe that medicine ought to have no role other than taking care of the interests of patients. If there are not enough resources for that, it should insist that more are brought in. This is our notion of 'societal perspective'.

\section{References}

1. Alameri M, Epstein M, Johnston A. Generic and therapeutic substitutions: are they always ethical in their own terms? Pharm World Sci. 2010;32(6):691-5.

2. Simoens S. Generic and therapeutic substitution: ethics meets health economics. Int J Clin Pharm. 2011;33(3):469-70.

M. N. Al Ameri $(\bowtie)$ · A. Johnston

William Harvey Research Institute, London, UK

e-mail: m.al-ameri@qmul.ac.uk

\section{Epstein}

Barts and The London School of Medicine and Dentistry,

London, UK 